\title{
Design of an E-Learning Resource Allocation Model from the Perspective of Educational Equity
}

\author{
https://doi.org/10.3991/ijet.v17i03.29425 \\ Caiyan Jiang \\ College of Humanities, Yantai Nanshan University, Yantai, China \\ haoxindi@nanshan.edu.cn
}

\begin{abstract}
Nowadays, e-learning and ubiquitous learning have been very common learning methods. Considering the increasing importance of e-learning in public education, it is very necessary to analyze and study the current situation of e-learning resource allocation, as it will provide useful reference for the promotion of educational equity and rational allocation of educational resources across China. However, there have only been a few quantitative and practical studies on the balanced allocation of e-learning resources. To this end, taking English education as an example, this paper designed an e-learning resource allocation model from the perspective of education equity. First, a resource allocation model of e-learning resources was constructed, and the e-learning resource access request allocation and e-learning resource allocation methods were described in detail. Then, the e-learning resource allocation framework was constructed, and the e-learning resource allocation strategy was given from the perspective of education equity. The experimental results prove that the proposed elearning resource allocation model can effectively avoid wasting resources and realize rational distribution of, efficient access to and extensive sharing of resources.
\end{abstract}

Keywords-education equity, learning resources, e-learning, allocation of educational resources

\section{Introduction}

In actual educational practice, fair education demands rational allocation of opportunities and resources and good education quality. It is directly related to the specific implementation of public education [1-5]. Rational allocation of learning resources plays a very important role in safeguarding people's rights to education and improving the quality of education; in other words, people's rights to education should not be differentiated due to the unbalanced allocation of learning resources. This is also the common goal pursued by education and teaching systems at different levels [6-9]. Nowadays, with the emergence of various forms of learning resource services such as online learning and network resource libraries, e-learning and ubiquitous learning have become common learning methods for learners [10-14]. Considering the increasing im- 
portance of e-learning in public education, it has become relevant whether the e-learning resources, which contain massive amount of reference and learning materials, can be allocated in a rational and balanced manner [15-23]. Therefore, it is very necessary to analyze and study the current situation of e-learning resource allocation from the perspective of education equity, so as to provide useful reference for the promotion of educational equity and rational allocation of educational resources nationwide.

Wei et al. [24] adopted digital technology to analyze and manage dance learning resources, and on this basis, improved the understanding and reuse of such resources. It efficiently integrated relevant digital resources based on subjects and formed a set of resources covering various materials, which greatly improved the utilization rate of dance learning resources and realized "3D" dance teaching. Considering the problems in use of the traditional file system to manage the massive resources in e-teaching systems, such as the availability, scalability of the file system, reliability of data transmission and file read and write performance, Chen et al. [25] studied several distributed file systems that are frequently applied at present, and proposed a new storage architecture model based on distributed file system by taking into account the characteristics of teaching resources, which proved able to improve the performance and reliability of e-teaching systems. In view of the current distributed resource search in the education field, Jin et al. [26] proposed the concept of personalized search based on consumers' interests and designed a model for personalized interest analysis and personalized resource search. It also proposed a self-learning algorithm for information search and filtering, which can help educational resource distribution centers achieve intelligent management. A major breakthrough in modern education is the use of Internet technology in teaching. With its rich teaching resources and user-friendly interactions, online teaching has been considered as the preferred auxiliary teaching method by more and more colleges and universities. Xiao and Wang [27] introduced the concept of 3D online teaching resources, and proposed a teaching resource grid system model based on multi-agent distributed expert system, which realized the global integration and sharing of online resources and teaching resources through the grid technology.

So far, there has been some progress in the research on education equity and the theoretical research on the specific allocation of learning resources, but there has been little quantitative and practical research on the balanced allocation of e-learning resources, and little attention has been paid to the optimization and design related to the creation, use and sharing of e-learning resources. In order to effectively avoid the waste of resources and achieve rational distribution of, efficient access to and extensive sharing of resources, this paper took English education as an example and designed an elearning resource allocation model from the perspective of education equity. Section 2 of this paper constructs the e-learning resource allocation model and describes in detail the e-learning resources access request allocation and e-learning resource allocation methods, so as to achieve standardized and balanced management of the resource pool containing massive e-learning resources. Section 3 builds the e-learning resource allocation framework, and gives the e-learning resource allocation strategy from the perspective of education equity. The experimental results verify the feasibility of the proposed e-learning resource allocation model. 


\section{Resource access request allocation and resource allocation}

There are great differences in the time and content of the access requests for e-learning resources sent by different learners to the e-learning platform. Take English learning as an example. Online English learning resources can be divided into primary school, junior high school and senior high school English materials by grade of the learners, dictation training, situational conversation, words memorizing and daily English learning by learning mode, and CET6, TEM4, TEM8, NETEM and TOEFL by English test type. How to impose standardized and balanced management on the massive e-learning resources to achieve the rational distribution and extensive sharing of resources is the key to solving the research problem.

The resource allocation model based on massive e-learning resources consists of four subsystems - resource access request partitioning, resource access request coding, target resource division, and target resource coding. Figure 1 presents the model architecture. Through partitioning and coding, a queue of several resource access request tasks with fixed priorities can be generated. The ultimate goal of the model is to reasonably allocate the resource access requests to the resources, so as to achieve efficient matching of resource access requests with specific target resources and optimize the utilization rate of e-learning resources under the context of education equity.

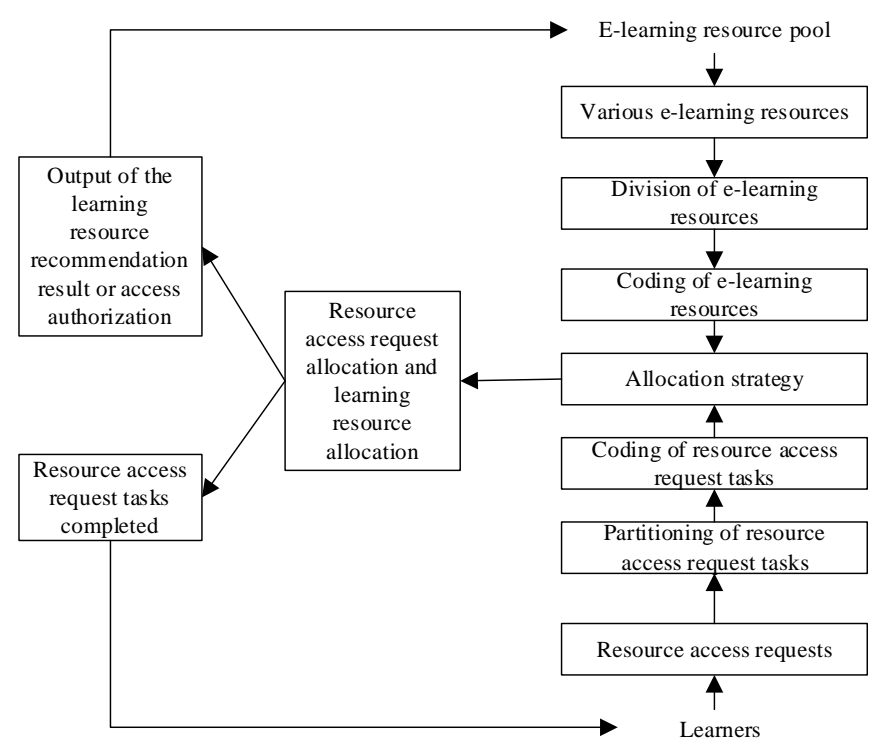

Fig. 1. E-learning resource allocation model 


\subsection{Resource access request allocation}

Suppose the $j$-th sub-request $O_{i, j}$ of the $i$-th resource access request is divided into several sub-requests $O_{i, j}^{\prime}$ executed in parallel, and the corresponding level of parallelism is represented by $O D_{i, j}$, then its value assignment is carried out according to Eq.(1):

$$
O D_{i, j}=\left\{\begin{array}{l}
0, \text { Scenario } 1 \\
l, \text { Scenario } 2
\end{array}\right.
$$

In the value assignment scenario 1 of $O D_{i, j}$, there are no sub-requests executed in parallel, and the requests are executed in the queue order of the requested tasks. In Scenario 2 , there are $l$ sub-requests executed in parallel, and the requests are executed in the parallel mode.

For the $j$-th sub-request of the $i$-th resource access request, the CPU, memory and elearning resources storage requirements for the e-learning resource allocation system of the e-learning platform and the requirements for application resources including software and e-learning resource pool can be characterized by the e-learning resources demand $O S_{i, j}$, and Eq.(2) gives its specific description:

$$
O S_{i, j}=\left\{O P E_{i, j}, O Z D V_{i, j}, O N R_{i, j}, O E Z_{i, j}, O X D D_{i, j}\right\}
$$

For the $j$-th sub-request of the $i$-th resource access request, the value of $O P E_{i, j}$ can be either 0 or 1 . If the resource access request needs to be executed in the Windows operating system environment, $O P E_{i, j}=0$; and if it needs to be executed in the Linux operating system environment, $O P E_{i, j}=1$.

For the $j$-th sub-request of the $i$-th resource access request, the application resource requirement $O X D D_{i, j}$ in its $O S_{i, j}$ contains several specific application resources:

$$
O S_{i, j}=\left\{O X D D_{i, j, 1}, O X D D_{i, j, 2}, O X D D_{i, j, 3}, \ldots, O X D D_{i, j, e}\right\}
$$

After the application resources required by all resource access requests are gathered and the duplicate application resources are eliminated, the actual set of application resources required SOBDR can be obtained, which contains $d$ types of application resource requirements. This set is characterized by Eq. (4):

$$
S O B D R=\left\{S O B D R_{1}, S O B D R_{2}, S O B D R_{3}, \ldots, S O B D R_{d}\right\}
$$

For the $j$-th sub-request of the $i$-th resource access request, its life cycle state $O Z_{i, j}$ has a total of 6 values $-0,1,2,3,4$ and 5 , corresponding to validation of the resource access request, waiting of the resource access request, pre-allocated resources for the resource access request, execution of the resource access request, termination of the resource access request and the execution failure of the resource access request, respectively. If the resource access request $O_{i}$ has $n$ sub-requests, Eq. (5) shows the expression of its total resource demand sequence $S O E_{i, n}$ :

$$
S O E_{i, e}=\left\{O S_{i, 1}, O S_{i, 2}, O S_{i, 3}, \ldots, O S_{i, n}\right\}
$$


The $Z D V$ requirement $S O Z D V_{i, n}$ of $O_{i}$ is expressed as Eq.(6):

$$
S O Z D V_{i, n}=\sum_{j=1}^{n} O Z D V_{i, j}
$$

The memory requirement $S O N R_{i, n}$ of $O_{i}$ is expressed as Eq.(7):

$$
\operatorname{SONR}_{i, n}=\sum_{j=1}^{n} O N R_{i, j}
$$

The e-learning resources storage requirement $S O E Z_{i, n}$ of $O_{i}$ is expressed as Eq.(8):

$$
\operatorname{SOEZ}_{i, n}=\sum_{j=1}^{n} O E Z_{i, j}
$$

The application resource capacity $S O X D D_{i, n}$ owned by $n$ sub-requests of $O_{i}$ is expressed as follows:

$$
\operatorname{SOXDD}_{i, n}=\{n, \underbrace{0,0, \ldots, 0}_{d-1 \uparrow 0}\}
$$

The total duration for the execution of $O_{i}$ is denoted as $O R O_{i, n}$. Through the above analysis, the attributes of the sub-request $O_{i}$ in the resource access request set before the allocation of the resource access requests to the e-learning resources can be described in detail as follows: $O_{i, j}=\left\{O D_{i, j}, O S_{i, j}, O R O_{i, j}, O Z_{i, j}\right\}$.

\subsection{Resource allocation}

In this paper, it is assumed that the e-learning resource allocation system of the elearning platform maps the e-learning resources stored in the server to the virtual machine layer and executes the resource access request tasks of the learners based on the mature virtualization technology. Therefore, under the context of education equity, the e-learning resource allocation should be implemented in the application layer and resource layer of the resource allocation model.

Let the resource allocation feature set of the virtual machine $U N_{i, j}$ be represented by $S_{i, j}=\left\{Z D V_{i, j}, N R_{i, j}, E Z_{i, j}, X D D_{i, j}, S E_{i, j}, G S_{i, j}\right\}$, corresponding to the CPU, memory, e-learning resources storage capacity, application resources, running status and failure rate of the server, respectively.

For the $j$-th resource allocation node of the $i$-th e-learning resource pool, $Z D V_{i, j}$ consists of the share of the CPU $Z D V X_{i, j}$ and the number of processors $Z D V Y_{i, j}$, the former being used to represent the size of the CPU resources used by the resource allocation node, and the latter being used to increase the processing speed of the processors:

$$
Z D V_{i, j}=\left\{Z D V X_{i, j}, Z D V Y_{i, j}\right\}
$$


For the $j$-th resource allocation node of the $i$-th e-learning resource pool, Eq. (11) describes in detail $X D D_{i, j, e}(e \in[k, E])$ that can allocate $E$ application resources:

$$
X D D_{i, j}=\left\{X D D_{i, j, 1}, X D D_{i, j, 2}, X D D_{i, j, 3}, \ldots, X D D_{i, j, e}\right\}
$$

After the application resources required by all resource allocation nodes are gathered and the duplicate application resources are eliminated, the actual set of application resources required TOBDR can be obtained, which contains the application resources corresponding to $w$ types of resource allocation nodes. This set is characterized by Eq. (12):

$$
T O B D R=\left\{T O B D R_{1}, T O B D R_{2}, T O B D R_{3}, \ldots, T O B D R_{w}\right\}
$$

The running state $S E_{i, j}$ of the $j$-th resource allocation node in the $i$-th e-learning resource pool also has two values: 0 and 1 . If the resource allocation node is available, $S E_{i, j}=0$; and if it is unavailable, $S E_{i, j}=1$. The specific description is as follows:

$$
S E_{i, j}=\left\{\begin{array}{l}
1, \text { Unavailable } \\
0, \text { Available }
\end{array}\right.
$$

Assuming that the $i$-th e-learning resource pool $S D_{i}$ contains $e$ virtual machine elearning resource allocation nodes, then:

$$
S D_{i}=\left\{U N_{i, 1}, U N_{i, 2}, U N_{i, 3}, \ldots, U N_{i, e}\right\}
$$

The sequence $S Z E_{i, e}$ of the resources owned by $S D_{i}$ can be expressed by Eq.(15):

$$
S Z D_{i, e}=\left\{S_{i, 1}, S_{i, 2}, S_{i, 3}, \ldots, S_{i, e}\right\}
$$

The total CPU value $S Z D V X_{i, e}$ available for allocation of $S D_{i}$ is expressed as:

$$
\operatorname{SOZDVX}_{i, n}=\sum_{j=1}^{e} Z D V X_{i, j}
$$

The memory capacity of $S N R_{i, e}$ available for allocation of $S D_{i}$ is expressed as:

$$
S N R_{i, e}=\sum_{j=1}^{e} N R_{i, j}
$$

The e-learning resource storage capacity $S E Z_{i, e}$ available for allocation of $S D_{i}$ is expressed as:

$$
S E Z_{i, e}=\sum_{j=1}^{e} E Z_{i, j}
$$

The application resource capacity $S X D D_{i, e}$ available for allocation of $S D_{i}$ is expressed as: 


$$
S X D D_{i, e}=\{e, \underbrace{0,0, \ldots, 0}_{w-1}\}
$$

Suppose that the maximum capacity of the virtual machine used is represented by $\operatorname{Max}_{i, e}$, that the minimum capacity by $\operatorname{Max}_{i, e}$, and that the number of virtual machines owned by the $n$-th resource pool by $p$. Eq.(20) and Eq.(21) are respectively the expressions of $\operatorname{MaxS}_{i, e}$ and $\operatorname{MaxS}_{i, e}$ of all virtual machines in $N$ resource pools:

$$
\begin{gathered}
\operatorname{Max} S=\operatorname{Max}\left\{\operatorname{Max}_{1, p}, \operatorname{Max}_{2, p}, \ldots, \operatorname{Max}_{n, p}\right\} \\
\operatorname{Min} S=\operatorname{Min}\left\{\operatorname{Min}_{1, p}, \operatorname{Min}_{2, p}, \ldots, \operatorname{Min}_{n, p}\right\}
\end{gathered}
$$

When the resource access requests are being executed, the resource allocation nodes allocate the reserved values of CPU, memory, and e-learning resource storage of each virtual machine with the e-learning resource pool as the unit, and the load balancing of the e-learning resource access requests is achieved through the distributed resource scheduling $D R S$, a functional component of vSphere Cluster.

Assuming that the current virtual machine $U N_{i, l}$ is about to allocate e-learning resources and is expected to execute the sub-request $O_{j, n}$ of the resource access request within a certain period of time, Eq.(22) gives the condition that the reserved value of CPU $S Z D V_{i, l}$ of the $l$-th virtual machine in the $i$-th resource pool needs to meet:

$$
S Z D V_{i, l} \leq Z D V_{i, l}-O Z D V_{j, n}
$$

The condition that the reserved value of memory $S N R_{i, l}$ of the $l$-th virtual machine in the $i$-th resource pool needs to satisfy is as follows:

$$
S N R_{i, l} \leq N R_{i, l}-O N R_{j, n}
$$

The condition that the reserved value of storage $S E Z_{i, l}$ of the $l$-th virtual machine in the $i$-th resource pool needs to satisfy is as follows:

$$
S E Z_{i, l} \leq E Z_{i, l}-O E Z_{j, n}
$$

After $S Z D V_{i, l}, S N R_{i, l}$ and $S E Z_{i, l}$ of the virtual machine are set, on condition that the virtual machine is able to respond to normal resource access requests, the distributed resource scheduling $D R S$ will transfer the reserved e-learning resources to virtual machines with high resource requirements to ensure the load of e-learning resources in the resource pool is balanced.

\section{Resource allocation framework and allocation process}

From the perspective of education equity, the e-learning resource allocation framework consists of the following components: the resource access request load agent, represented by $Q$, the resource access request load agent vector, represented by $q=\left\{q_{1}, q_{2}\right.$, 
$\left.\ldots, q_{m}\right\}$, the specific e-learning resources, represented by $R T$, and the $n$ types of learning resources that can be managed and controlled by the underlying hardware agent, represented by $T=\left\{t_{1}, t_{2}, \ldots, t_{n}\right\}$, the push service cost of e-learning resources, represented by $J G$, and the vector of service cost, represented by $U N_{X}$.

Then, the e-learning resource allocation from the perspective of education equity can be transformed into the process of solving an allocation ratio matrix $A$ of $n$ types of learning resources. $A$ can be regarded as a resource allocation scheme. Assuming that the proportion of $t_{j}$ used by $q_{i}$ is represented by $a_{i j}$, the set of feasible solutions $A$ composed of all possible $a$ is given in Eq. (25):

$$
A=\left\{a \mid 0 \leq a_{i j} \leq 1,0 \leq \sum_{i=1}^{m} a_{i j} \leq 1\right\}
$$

Rewrite the matrix $A$ into the form of a row vector, which is $A^{T}=\left(a_{1}, a_{2}, \ldots a_{m}\right)$, and let the resource use vector of $q_{i}$ be represented by $a_{i}=\left(a_{i 1}, a_{i 2}, \ldots a_{i n}\right)$, and then there is:

$$
\left[\begin{array}{ccccc} 
& Z D V & N R & \cdots & E Z \\
U N_{1} & a_{11} & a_{12} & \cdots & a_{1 n} \\
U N_{2} & a_{21} & a_{22} & \cdots & a_{2 n} \\
\cdots & \cdots & \cdots & \cdots & \cdots \\
U N_{m} & a_{n 1} & a_{m 2} & \cdots & a_{m n}
\end{array}\right]
$$

There is a certain correlation between the learners' satisfaction with the quality of the e-learning resources push services for their different resource access requests and the proportion of e-learning resources effectively used by learners. Therefore, a utility function $G_{i}\left(a_{i 1}, a_{i 2}, \ldots, a_{i n}\right)$ was constructed in this paper to characterize learners' satisfaction with the e-learning resources.

The constructed utility function can be expressed as $G_{i}\left(a_{i}\right)=\mu_{1} a^{z i 1}{ }_{i 1}+\mu_{2} a^{z i 2}{ }_{i 2}+\ldots+\mu_{n} a^{z i-}$ ${ }_{i n}$. When $0 \leq z_{i j} \leq 1$, the utility function is a monotonic concave function. From the expression of $G_{i}\left(a_{i}\right)$, it can be seen that the key to improving learners' satisfaction with the e-learning resources push services is to achieve a balance between different e-learning resources. Simply increasing the use ratio of a certain type of learning resources is not enough to achieve the desired education equity.

Assuming that the total utility function of the e-learning resource allocation scheme $a$ is represented by $Q(a)$, there is:

$$
Q(a)=\sum_{i=1}^{n} G_{i}\left(a_{i}\right)
$$

When $Q(a)$ reaches the maximum, its corresponding solution $a_{\max }$ is the optimal solution to the allocation of e-learning resources for the system. The constraints are as follows: 1) $a_{i} \in A$; 2) $H_{i}(J G)=G_{i}\left(a_{i}\right)-J G a^{T}{ }_{i}$ is satisfied for each $q_{i}$; 3) For any $t_{j}$ there is:

$$
\sum_{i=1}^{m} a_{i j}=1
$$


Only when the constraints shown in Eq. (28) are satisfied at the same time, is $a_{i}$ in a balanced state in the e-learning resource push service cost vector $J G$. Further, the balanced state of e-learning resource allocation can be defined as the situation where the resource allocation scheme is feasible, each $q_{i}$ has obtained the maximum utility with $J G$, and each type of learning resources has been fully utilized.

The e-learning resource allocation strategy from the perspective of education equity is to first optimize the resource access requests and the specific e-learning resources according to a certain strategy, and then achieve the allocation of resource access requests and e-learning resources through matching and mapping, as shown in Figure 2. The specific process is described as follows:

- Step1: The e-learning resource allocation system receives the e-learning resources access requests from the learners, and performs task analysis;

- Step2: Based on the partitioning strategy, it completes the partitioning of e-learning resources access request tasks;

- Step3: The system encodes the e-learning resources access request tasks by reference to the priorities of task execution, and insert them into the resource access request task pool to form a queue of tasks to be executed;

- Step4: Based on the allocation strategy, the system matches the e-learning resource requirements for the tasks to be executed, and enables the resource allocation nodes that meet the requirements for resource allocation;

- Step5: The system outputs the learning resource recommendation results or authorizes access to these resources.

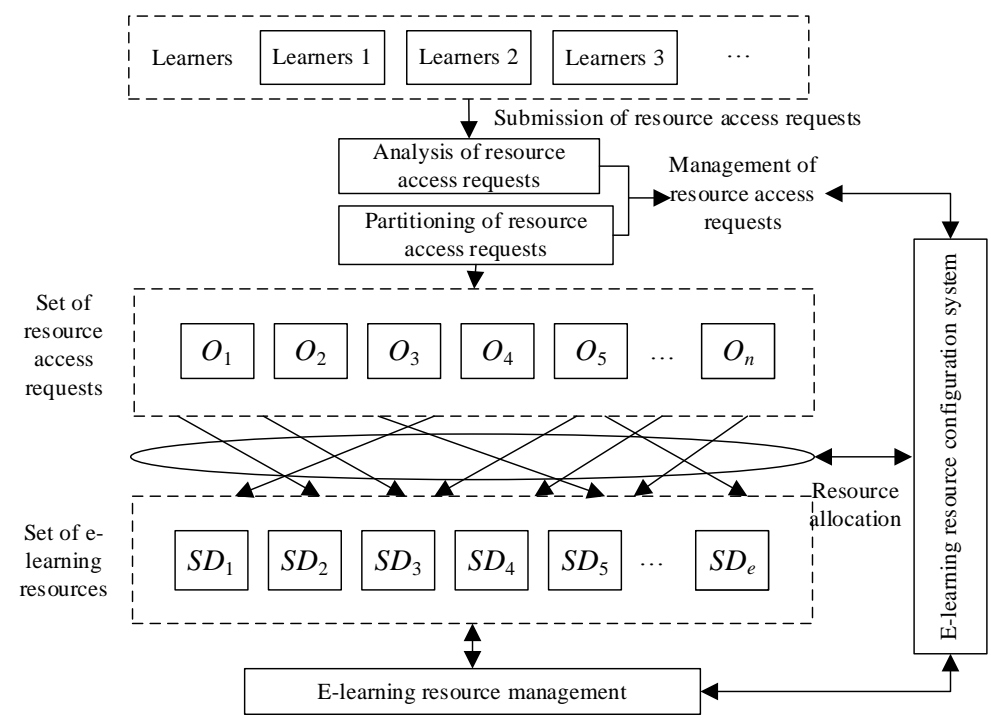

Fig. 2. E-learning resource allocation strategy from the perspective of education equity 


\section{Experimental results and analysis}

In this paper, the information of learning resources on highly-visited online English learning websites were manually collected, which involves two types - course learning resources and auxiliary test resources. Course learning resources include online open courses, courseware, images, videos, audios and animations; and auxiliary test resources include test questions, test papers, case analysis, FAQs and associated literatures and catalogue indexes of other resources. Online English learning websites include primary and secondary school English education, pre-school English education, vocational English education, higher English education, English examinations and certificate tests, national entrance test of English for MA/MS candidates (NETEM), English training for overseas studies, and English essay writing.

From Tables 1 and 2, it can be seen that the amounts and distributions of e-learning resources are different on different types of online English learning websites. There are more e-learning resources on the websites of higher English education, English examination and certificate tests, NETEM, and English training for overseas studies, and fewer on those of vocational English education and primary and secondary school English education. Judging from the types of resources, there are more e-learning resources in the forms of images, videos, test questions and test papers, and fewer in the forms of online open courses, FAQs and animations.

Figure 3 and Figure 4 respectively show the resource capacity of nodes before and after the allocation by the proposed resource allocation model. According to the results shown in these figures, before the proposed resource allocation model was used, the elearning resource allocation system allocated resources randomly, and since the capacities of e-learning resource nodes are quite different, each resource allocation node had a different share of storage and transmission. After the proposed resource allocation model was used, the system chose the most appropriate resource allocation nodes according to the priorities of resource access requests, which ensured that the e-learning resource storage and transmission percentages of the resource allocation nodes corresponding to the load of each resource access request are relatively balanced, and that the situation where some resource allocation nodes are fully occupied and other nodes are idle would not happen due to the differences between nodes in e-learning resource capacity. This shows that the proposed resource allocation model can effectively improve the unbalanced load of e-learning resource access requests.

Table 1. Allocation of course learning resources on different types of Online English learning websites

\begin{tabular}{|l|c|c|c|c|c|c|c|}
\hline & $\begin{array}{c}\text { Online open } \\
\text { course }\end{array}$ & Courseware & Image & Video & Audio & Animation & Total \\
\hline $\begin{array}{l}\text { Primary and secondary } \\
\text { school English education }\end{array}$ & 1 & 21 & 1528 & 615 & 182 & 7 & 9275 \\
\hline Preschool English education & 3 & 1 & 1142 & 18 & 253 & 162 & 13261 \\
\hline Vocational English education & 1 & 1 & 2 & 1 & 1 & 6 & 13284 \\
\hline Higher English education & 4 & 527 & 2375 & 162 & 415 & 8 & 21138 \\
\hline
\end{tabular}


Paper-Design of an E-Learning Resource Allocation Model from the Perspective of Educational Equity

\begin{tabular}{|l|c|c|c|c|c|c|c|}
\hline $\begin{array}{l}\text { English exams and certificate } \\
\text { tests }\end{array}$ & 1 & 2 & 1428 & 12 & 25 & 4 & 8152 \\
\hline NETEM & 1 & 182 & 1027 & 126 & 362 & 115 & 13725 \\
\hline $\begin{array}{l}\text { English training for overseas } \\
\text { tudies }\end{array}$ & 1 & 1 & 628 & 182 & 1748 & 362 & 12483 \\
\hline English essay writing & 2 & 135 & 685 & 41 & 13 & 2 & 19284 \\
\hline Other websites & 2 & 14 & 825 & 548 & 928 & 7 & 8849 \\
\hline Total & 528 & 2294 & 17485 & 3625 & 4821 & 1329 & 194857 \\
\hline
\end{tabular}

Table 2. Allocation of auxiliary test resources on different types of online English learning websites

\begin{tabular}{|l|c|c|c|c|c|c|c|}
\hline & $\begin{array}{c}\text { Test } \\
\text { questions }\end{array}$ & $\begin{array}{c}\text { Test } \\
\text { papers }\end{array}$ & $\begin{array}{c}\text { Case } \\
\text { analysis }\end{array}$ & FAQs & $\begin{array}{c}\text { Associated } \\
\text { literatures }\end{array}$ & $\begin{array}{c}\text { Catalogue indexes } \\
\text { of other resources }\end{array}$ & Total \\
\hline $\begin{array}{l}\text { Primary and secondary } \\
\text { school English education }\end{array}$ & 148 & 216 & 2 & 1 & 924 & 1529 & 9275 \\
\hline $\begin{array}{l}\text { Preschool English educa- } \\
\text { tion }\end{array}$ & 326 & 31 & 2 & 1 & 8729 & 1046 & 12817 \\
\hline $\begin{array}{l}\text { Vocational English edu- } \\
\text { cation }\end{array}$ & 7 & 174 & 1 & 33 & 1829 & 95 & 13284 \\
\hline Higher English education & 1231 & 2340 & 322 & 42 & 7585 & 8529 & 13261 \\
\hline $\begin{array}{l}\text { English exams and certif- } \\
\text { icate tests }\end{array}$ & 1202 & 1456 & 447 & 26 & 2519 & 428 & 6382 \\
\hline NETEM & 333 & 421 & 132 & 146 & 7218 & 13 & 13725 \\
\hline $\begin{array}{l}\text { English training for over- } \\
\text { seas studies }\end{array}$ & 755 & 563 & 85 & 26 & 4518 & 1629 & 23975 \\
\hline English essay writing & 251 & 114 & 8 & 36 & 3759 & 674 & 8152 \\
\hline Other websites & 24 & 1472 & 58 & 26 & 1528 & 452 & 8849 \\
\hline Total & 3528 & 6318 & 294 & 297 & 68594 & 36284 & 194857 \\
\hline
\end{tabular}


Paper-Design of an E-Learning Resource Allocation Model from the Perspective of Educational Equity

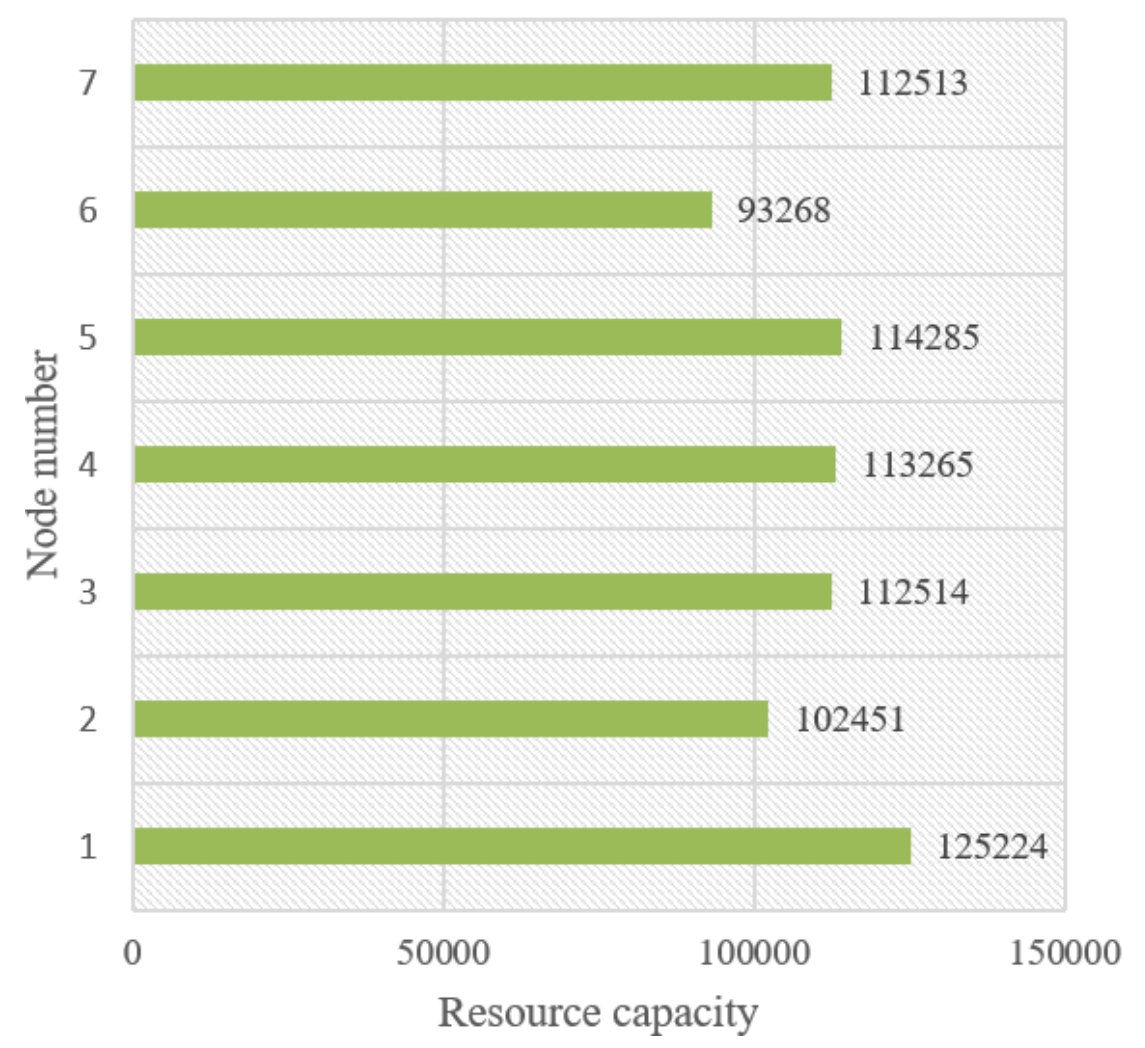

Fig. 3. Resource transmission capacity before resource allocation 


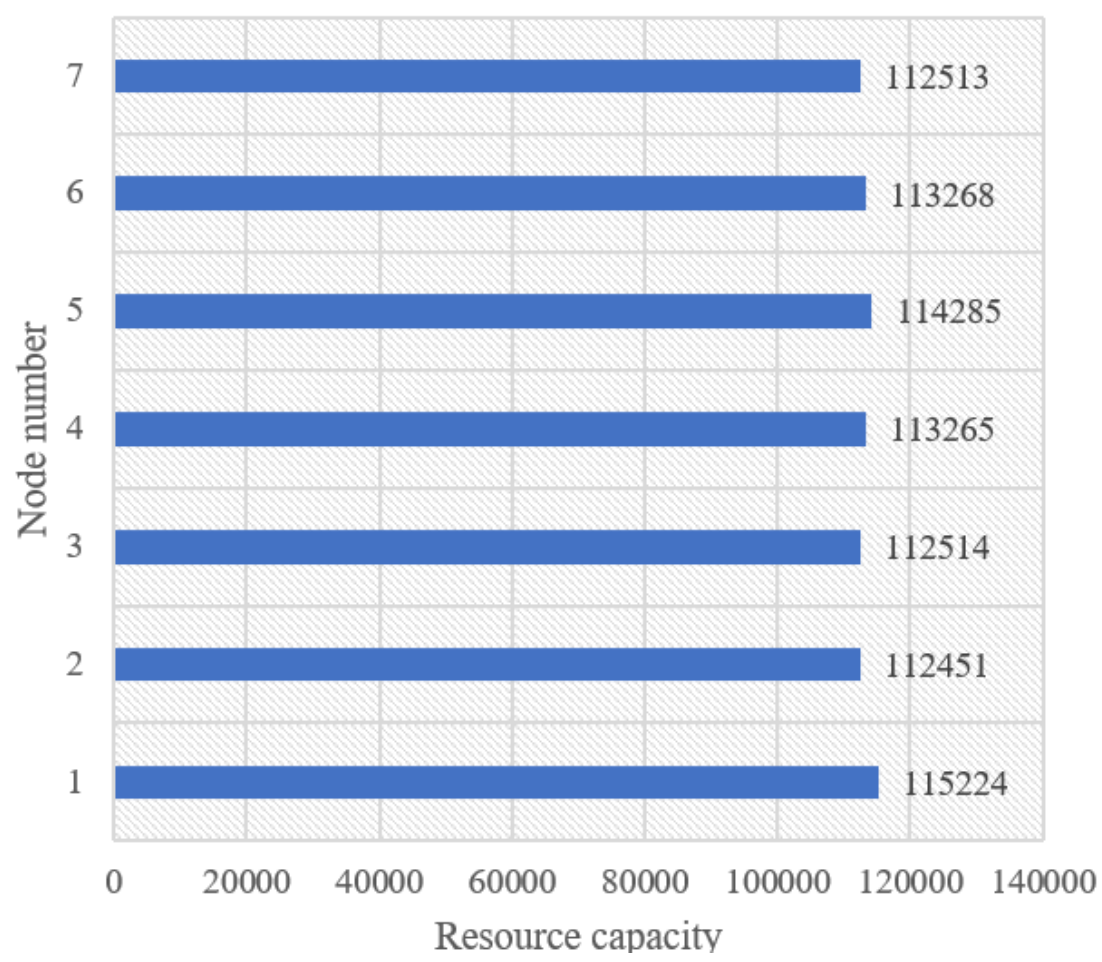

Fig. 4. Resource transmission capacity after resource allocation

Figures 5 and 6 show the variation curves of the amount of redundant resources and resource transmission overheads with different sizes of resource pools. It can be seen that, with the same resource pool size, the amount of redundant resources generated by the proposed resource allocation model was reduced by nearly $1 / 3$ compared with that before the proposed model was used, and that the transmission overhead of e-learning resources was obviously better than that before the proposed model was used, indicating that the proposed model can effectively avoid wastes of resources, achieve rational distribution of resources and allow efficient access to and sharing of e-learning resources. 


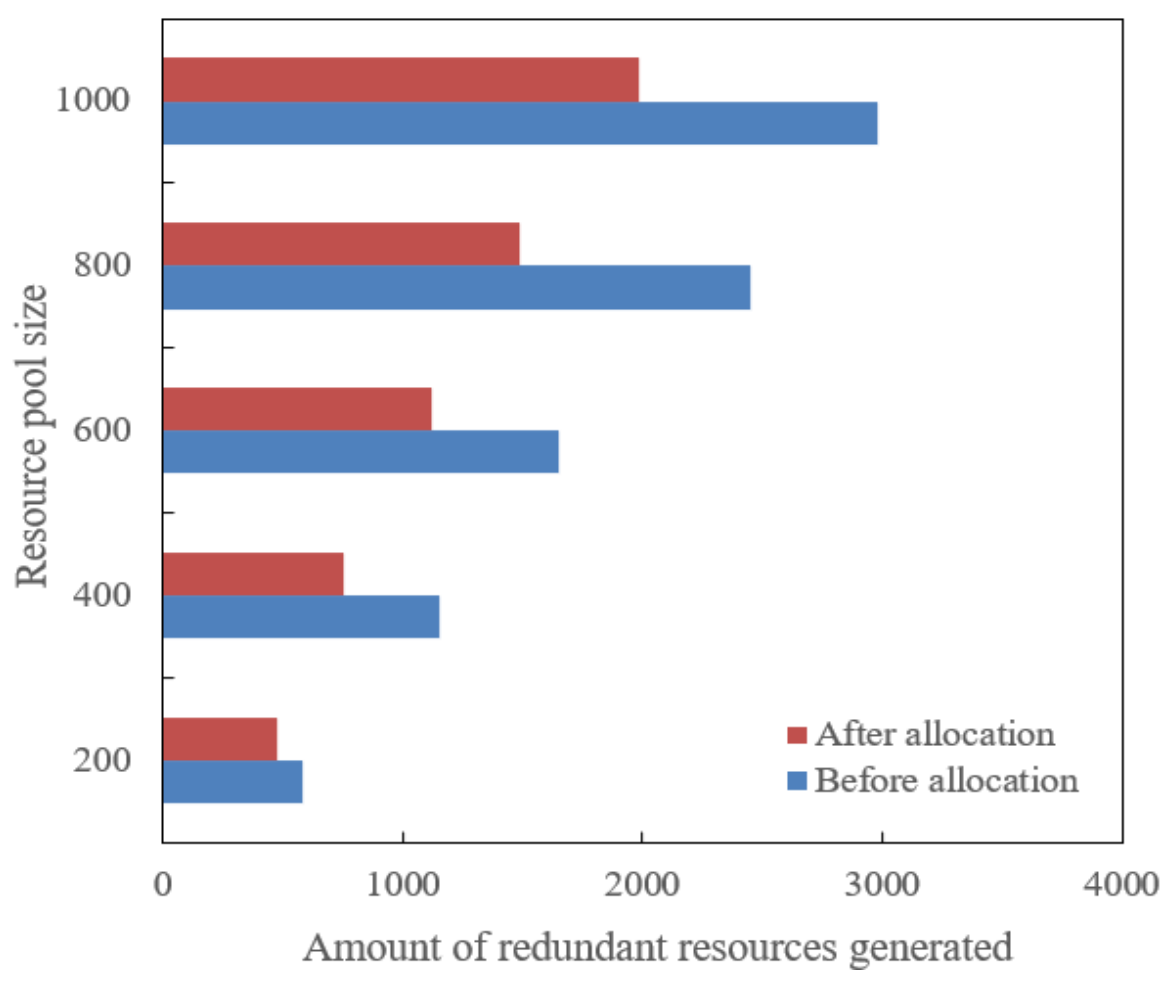

Fig. 5. Variation curve of the amount of redundant resources with different sizes of resource pools 


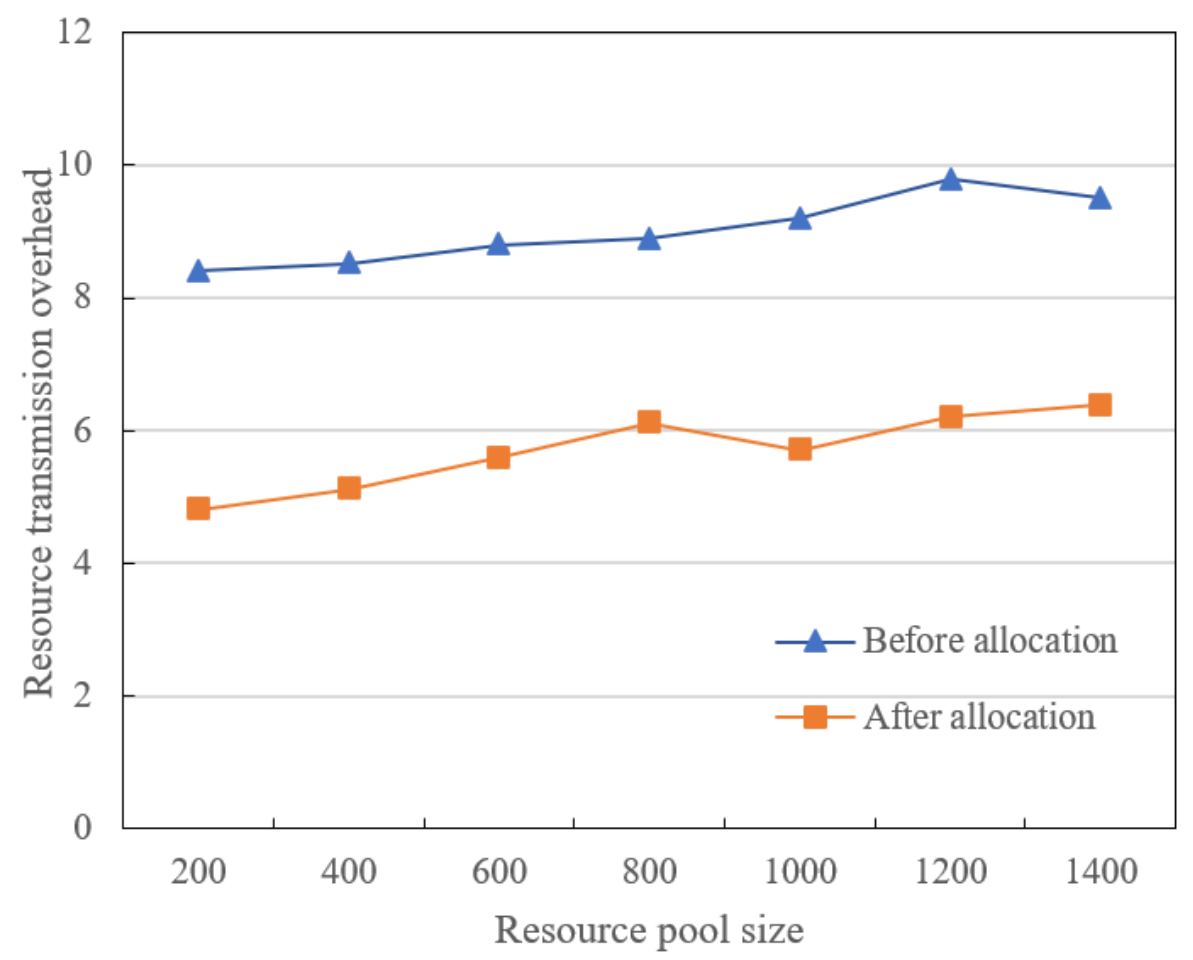

Fig. 6. Variation curve of resource transmission overhead with different sizes of resource pools

\section{Conclusions}

Taking English education as an example, this paper designed an e-learning resource allocation model from the perspective of education equity. It constructed the e-learning resource allocation model and e-learning resource allocation framework and described in detail the methods to allocate e-learning resource access requests and e-learning resources. At last, it gave the e-learning resource allocation strategy from the perspective of education equity. The experimental results and analysis section summarized the course learning resources and auxiliary test resources allocated on different types of online English learning websites, and compared the resource transmission capacities of nodes before and after the proposed resource allocation model was used, which proves that the proposed resource allocation model can effectively improve the problem of unbalanced load of network resource access requests. The variation curves of the amount of redundant resources and resource transmission overheads with different sizes of resource pools were drawn, proving that the proposed e-learning resource allocation model can effectively avoid wasting resources and realize rational distribution of, efficient access to and extensive sharing of resources. 


\section{References}

[1] Zhang, X., Yu, S. (2015). Deaf-mute students physical health development strategy research in the perspective of education fair equalization. The Open Cybernetics \& Systemics Journal, 9(1): 1640-1645. https://doi.org/10.2174/1874110X01509011640

[2] Chen, N, Zhang, X.Q. (2014). Study on fair education, social mobility and long-term economic growth. Bio technology: An Indian Journal, 10(12): 5900-5909.

[3] Hollier, S. (2017). Technology, education and access: A'fair go'for people with disabilities. In Proceedings of the 14th International Web for All Conference, 1-2. https://doi.org/ $10.1145 / 3058555.3058557$

[4] Ma, L., Xu, J., Xiao, P. (2011). Multimedia teaching techniques are the effective fair education approach. In 2011 International Conference on Multimedia Technology, 3136-3138. https://doi.org/10.1109/ICMT.2011.6001890

[5] Vossen, P.H. (2016). Distributive fairness in educational assessment. In International Workshop Soft Computing Applications, 634: 381-394. https://doi.org/10.1007/978-3-31962524-9_29

[6] Tanveer, H., Balz, T., Sumari, N.S., Shan, R.U., Tanweer, H. (2020). Pattern analysis of substandard and inadequate distribution of educational resources in urban-rural areas of $\mathrm{Ab}-$ bottabad, Pakistan. GeoJournal, 85(5): 1397-1409. https://doi.org/10.1007/s10708-019$\underline{10029-x}$

[7] Zan, C. (2019). A Distributed distribution and scheduling algorithm of educational resources based on vector space model. International Journal of Emerging Technologies in Learning, 14(4): 58-72. https://doi.org/10.3991/ijet.v14i04.10132

[8] Brown, D.W., Ford, V., Ghafoor, S.K. (2020). A framework for the evaluation of parallel and distributed computing educational resources. In 2020 IEEE International Parallel and Distributed Processing Symposium Workshops (IPDPSW), 261-268. https://doi.org/10. 1109/IPDPSW50202.2020.00057

[9] Marjit, U., Kumar, P. (2020). Towards a decentralized and distributed framework for Open Educational Resources based on IPFS and Blockchain. In 2020 International Conference on Computer Science, Engineering and Applications (ICCSEA), 1-6. https://doi.org/10.1109/ ICCSEA49143.2020.9132841

[10] Naim, A., Alahmari, F. (2020). Reference Model of E-learning and Quality to Establish Interoperability in Higher Education Systems, International Journal of Emerging Technologies in Learning, 15(2): 15-28. https://doi.org/10.3991/ijet.v15i02.11605

[11] Khlifi, Y. (2020). An Advanced Authentication Scheme for E-evaluation Using Students Behaviors Over E-learning Platform, International Journal of Emerging Technologies in Learning, 15(4): 90-111. https://doi.org/10.3991/ijet.v15i04.11571

[12] Ngo, L.B., Srinath, A.T., Denton, J., Ziolkowski, M. (2018). Unifying computing resources and access interface to support parallel and distributed computing education. Journal of Parallel and Distributed Computing, 118: 201-212. https://doi.org/10.1016/j.jpdc.2018.02.020

[13] Utomo, M.N.Y., Sudaryanto, M., Saddhono, K. (2020). Tools and strategy for distance learning to respond COVID-19 pandemic in Indonesia. Ingénierie des Systèmes d'Information, 25(3): 383-390. https://doi.org/10.18280/isi.250314

[14] Wen, F.F. (2010). Study on the regional distribution of higher education resources in China - Based on the "Chinese universities evaluation ranking in 2010". Wuhan Daxue Xuebao (Xinxi Kexue Ban)/Geomatics and Information Science of Wuhan University, 35(S1): 104108. 
[15] Wijaya, M.C., Maksom, Z., Abdullah, M.H.L. (2021). A brief of review: Multimedia authoring tool attributes. Ingénierie des Systèmes d'Information, 26(1): 1-11. https:// doi.org/10.18280/isi.260101

[16] Xue, J. (2014). Design of the distributed network for English education resources. In 2014 Sixth International Conference on Measuring Technology and Mechatronics Automation, 255-259. https://doi.org/10.1109/ICMTMA.2014.64

[17] Kotsampopoulos, P., Messinis, G., Vassilakis, A., Kleftakis, V., Rigas, A., Hatziargyriou, N. (2014). Laboratory education on distributed energy resources making use of an advanced infrastructure. In MedPower 2014, 1-6. https://doi.org/10.1049/cp.2014.1673

[18] Wang, W. (2011). The design and application for distributed educational resource platform based on digital campus. In 2011 International Conference on E-Business and E-Government (ICEE), 1-4. https://doi.org/10.1109/ICEBEG.2011.5882477

[19] Cherednichenko, O., Yangolenko, O., Liutenko, I. (2012). Issues of model-based distributed data processing: higher education resources evaluation case study. The international proceedings volume of ICTERI, 848: 147.

[20] Anam, K., Asyhar, B., Saddhono, K., Setyawan, B.W. (2021). E-SIP: Website-based scheduling information system to increase the effectivity of lecturer's performance and learning process. Ingénierie des Systèmes d'Information, 26(3): 265-273. https://doi.org/10.18280 $\underline{\text { /isi.260303 }}$

[21] Cheng, J.J., Huang, J.J. (2011). The study on education resources construction of digital community based on distributed technology. In Advanced Materials Research, 271: 785790. https://doi.org/10.4028/www.scientific.net/AMR.271-273.785

[22] Kripka, R.M.L., Oro, N.T., Kripka, M. (2005). Workload distribution in institutions of higher education: A formularization for the maximization of the human resources utilization. Ciencia y Engenharia/ Science and Engineering Journal, 14(1): 67-74.

[23] Feng, X., Jia, C., Yang, J. (2008). Semantic web recommendation model of distributing educational resource. In 2008 International Conference on Computer Science and Software Engineering, 3: 415-418. https://doi.org/10.1109/CSSE.2008.1134

[24] Wei, M., Wang, H., Liu, W. (2018). System framework and information model for a distributed dance teaching resource repository. In 2018 IEEE 15th International Conference on eBusiness Engineering (ICEBE), 335-339. https://doi.org/10.1109/ICEBE.2018.00063

[25] Chen, P., Li, J., Gou, X. (2011). Research of distributed file system based on massive resources and application in the network teaching system. IET Conference Publications, 154158.

[26] Jin, Y., Fang, Z., Zhang, Y., Wei, C. (2009). The application of personalized distribution system in distributed teaching resource. In 2009 International Conference on Computational Intelligence and Software Engineering, 1-4. https://doi.org/10.1109/CISE.2009.5365522

[27] Xiao, L., Wang, Z. (2009). Teaching resource grid system model based on multi-agent distributed expert system. In 2009 International Conference on Computational Intelligence and Software Engineering, 1-6. https://doi.org/10.1109/CISE.2009.5363001

\section{$7 \quad$ Author}

Caiyan Jiang was born on 21th, December 1983 in Longkou City, Shandong Province, China. She received B.A. degree of English from Qiqihaer University in 2006. She started her teaching career in July, 2006 in Department of Public Foreign Language Teaching, Yantai Nanshan University Since 2006. She has authored more than 10 pa- 
pers in English teaching and literature. She has participated to compile several textbooks and authored a book Innovation and Practice of Independence English Learning in the Internet Environment and a CSCD paper of Effectiveness of English Classroom Teaching Reform in Cross-cultural Context in Evaluation of English Education and Teacher Education.

Article submitted 2022-01-05. Resubmitted 2021-02-10. Final acceptance 2022-02-11. Final version published as submitted by the author. 